\title{
A Descriptive Study to Assess the Knowledge of Mothers Regarding the Nutrition for Under Five Children in Selected Areas of Bagalkot with a View to Develop a Self Instructional Module
}

\author{
Chetan S Patali* \\ Department of Psychiatric Nursing, Rajiv Gandhi University of Health Sciences, India \\ *Corresponding author: Chetan S Patali, Department of Psychiatric Nursing, Rajiv Gandhi University of Health Sciences, Bangalore, Karnataka, India
}

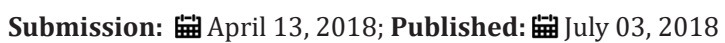

\begin{abstract}
In India it is observed from various nutrition surveys that the nutritional status of pregnant and lactating mothers and infants is not satisfactory, this is probably due to lack of basic knowledge regarding proper nutrition and wrong customs prevalent in the community besides non-availability and low intake of food. To bring about changes in the knowledge in the mothers regarding nutrition[1], an attempt was made to assess mothers' knowledge and hence to improve it based on their learning needs through an instructional module. Children are future of society and mothers are guardian of that future [2]. Hence to ensure sound foundation and secure future of any society health and nutrition of their children need protection. Children below five years of age require most attention, as this is the period of rapid growth and development, which makes them highly vulnerable to malnutrition. Malnutrition in this stage has far reaching consequences on child's future by severely effecting child's physical and mental development [2]. Yet malnutrition among children is widely prevalent in South East Asia region more so in India. As per available data about half of children in this age group suffer from different grade of malnutrition. Malnutrition in turns weakens the immune system of the child, thereby contributes to more than $50 \%$ of deaths associated with infectious diseases among this age group [3].
\end{abstract}

Objectives:

A. To assess the knowledge of mothers regarding the nutrition for under five children.

B. To find out the association between the mother's knowledge regarding nutrition for under-five children with selected socio demographic variables[4].

C. To develop an instructional module regarding nutrition for under-five children based on their learning needs.

Method: This was descriptive study total 100 subjects were selected through non-probability purposive sampling technique. Exploratory design was used. Data was collected by structured questionnaire. Data collected under the 2 sections (socio-demographic data and knowledge regarding nutrition for less than five).The reliability of the tool was established by Split Half method formula. The reliability result of knowledge was r=0.7015. Prepared self instructional module regarding nutrition was developed after content validity of the tool was established by six experts.Data was analyzed by using descriptive and inferential statistical in terms of frequency, percentage, mean, standard deviation, Chi-square values[5].

Result: The data were analyzed by descriptive and inferential statistics. Out of 100 samples the data were shows that $42 \%$ of the subjects were between 26-30 years, and 08\% was in between 31-35 years[6], Majority (72\%) of the sample was housewife and the rest 28\%. employee.The results shows that majority of the mothers $41 \%$ had satisfactory knowledge level ( 41 mothers), inadequate knowledge about $36 \%$ ( 36 mothers) and $23 \%$ ( 23 mothers) were had adequate knowledge. There is significant association between knowledge with age, educational status of mother, occupation of mother, religion, type of family, total number of fewer thanfives in the family, monthly income of the family, and place of residence.

Interpretation and conclusion: Findings of the study indicates that majority of the mothers $41 \%$ had satisfactory knowledge level (41 mothers), inadequate knowledge about 36\% (36 mothers) and 23\% (23 mothers) were had adequate knowledge regarding nutrition for under five child. The study had implication not only in the field of nursing, but also in other disciplines. Education programme should give importance to equip the mothers with adequate knowledge regarding nutrition thereby preventing from threat of nutritional deficiencies[7].

Keywords: Mothers; Knowledge regarding nutrition for under five;Self-instructional module

\section{Introduction}

"Children are future of society and mothers are guardian of that future". First and foremost, health, safety, and nutrition for the young child is written on behalf of young children everywhere. Ultimately, it is the children who benefit from having parents who understand and know how to protect and promote their safety 
and well-being by knowing regarding nutrition. Nutrition is the provision, to cells and organisms, of the materials necessary (in the form of food) to support life. Many common health problems can be prevented or alleviated with a healthy diet. Nutrients are organic \& in organic complexes contained in food. There are six major classes of nutrients those are mainly carbohydrates, fats, minerals, protein, vitamins and water. These nutrient classes can be categorized as either macronutrients (needed in relatively large amounts) or micronutrients (needed in smaller quantities). The macronutrients include carbohydrates, fats, protein and water. The micronutrients are minerals and vitamins [8].

The macronutrients (excluding water) provide structural material (amino acids from which proteins are built and lipids from which cell membranes and some signaling molecules are built), energy. Vitamins, minerals, fiber and water do not provide energy, but are required for other reasons. A third class of dietary material, fiber is also required for both mechanical and biochemical reasons, although the exact reasons remain unclear.

Mother is the one who take care of the child, it is very important that she should need to have knowledge regarding care of under five and nutrition which they need, under fives are "age in-between $0-5$ years of child". Healthy eating and physical activity are essential for growth and development in childhood. To help children develop healthy eating patterns from an early age, it is important that the food and eating patterns to which they are exposed-both at home and outside the home-are those which promote positive attitudes to good nutrition [9].

\section{Background of the Study}

Balanced diet is essential for normal activities of life. Since there is enough food available, it can be improved through proper education and awareness. Good nutrition and proper feeding programs prevent illness and disabilities. Malnutrition continues to be an underlying cause of morbidity and mortality in children under five years of age. Children are more vulnerable to suffer from nutritional deficiencies. Certain socio-economic, biological, environmental and behavioral factors increase the risk and need to be identified early to promote health and prevent disease [9].

Nutritionally educated mothers can bring up their children in a healthier way. Improving breast feeding techniques not only provide adequate nutrition to the infant but can also decrease the frequency of gastroenteritis and respiratory infections and reduce the number of infant deaths. Colostrum should be given to the neonate as it is a source of proteins, antibodies and vitamins. Malnutrition and micronutrient deficiencies during the weaning period are reported from many developing countries [10]. These deficiencies can be prevented by complementary feeding i.e. the addition of energy through non-human milk and semisolid or solid foods to children diet as described by WHO [2].

More than 3.5 million children fewer than five die unnecessarily each year in Asia due to the underlying cause of under nutrition and millions more are permanently disabled by the physical and mental effects of a poor dietary intake in the earliest months of life. By the time children reach their second birthday, if undernourished, they could suffer irreversible physical and cognitive damage, impacting their future health, economic well-being and welfare. The consequences of insufficient nourishment continue into adulthood and are passed on to the next generation as undernourished girls and women have children of their own. Under nutrition includes a wide array of effects including intrauterine growth restriction (IUGR) resulting in low birth weight; underweight, a reflection of low weight-for-age; stunting, a chronic restriction of growth in height indicated by a low height-for-age; wasting, an acute weight loss indicated by a low weight-for-height; and less visible micronutrient deficiencies. Under nutrition is caused by a poor dietary intake that may not provide sufficient nutrients, and/or by common infectious diseases, such as diarrhoea. These conditions are most significant in the first two years of life, highlighting the importance of nutrition in pregnancy and the window of opportunity for preventing under nutrition from conception through 24 months of age [11].

\section{Objectives}

To help in clarifying the study the following objectives were formulated:

A. To assess the knowledge of farmers regarding sunburn and its prevention.

B. To find out the association between the knowledge of farmers regarding sunburn and its prevention with selected socio demographic variables [12].

C. To develop and distribute an information booklet on sun burn and its prevention among farmers.

\section{Hypothesis}

H1: More than $50 \%$ of farmers will have inadequate knowledge regarding sunburn and its prevention.

H2: There will be significant association between knowledge regarding sunburn and its prevention with their selected sociodemographic variables [13].

\section{Methodology \\ Setting of the study}

It refers to the area where the study is conducted. It may be natural setting or laboratory setting depending upon the study topic and researchers choice. The study was conducted in Bagalkot and Mothers were selected by the convenient sampling method [14].

\section{Population}

Population includes all possible elements that could be included in research. For the present study, Population of the study is mothers of under-fivewhom residing at selected areas of Bagalkot (i.e. Vidyagiri, Old Bagalkot and Navanagar) [15].

\section{Sample}

Sample is a small portion of the population selected for observation and analysis. The sample for the present study composed of 100 Mothers of selected areas of Bagalkot [16]. 


\section{Sampling technique}

For the present study convenient sampling method was selected and considered appropriate. Convenient sampling involves the selection of the population in the sample which appear convenient to him / to the management of the organization where he is conducting research. The sample for the study was drawn from the Mothers of selected areas of Bagalkot [17].

\section{Pilot study}

Pilot study is a small preliminary investigation of the same general characteristics of the major study.After getting formal permission from the office of the District Health \& Family Welfare Office, NavanagarBagalkot. The investigator conducted the pilot study [18]. The sample size for pilot study was 10 mothers.

The purpose and usefulness of the pilot study as follows:

1. To identify the problem related to study

2. To examine reliability of tool

3. To refine research methodology

4. To get live experience of research study

5. To determine feasibility of proposed study.

\section{Plan for data analysis}

Analysis is the systematic organization and synthesis of research data and the testing of the research hypothesis using that data.The data obtained will be analyzed by using frequency, percentage, mean, standard deviation, descriptive and inferential statistics. The data will be presented under the following headings [19].

\section{Part I: Demographic data}

Description of sample characteristics Baseline data containing sample characteristics (socio-demographic data) would be analyzed using frequency and percentage [20].

\section{Part II: Knowledge score}

The knowledge of the mothers would be analyzed using frequency, percentage, mean percentage and standard deviation.

\section{Part III: Association between knowledge score and selected demographic data}

Association between knowledge scores and selected demographic data such as age, educational status of mother, occupation of mother, religion, type of family [21], marital status of the mother, total number of under fives in the family, monthly income of the family and place of residence would be found out by using Chi-Square test. The level of significance would be set at $\mathrm{p}<0.05$ level to test the significance of association. This level is often used as a standard for testing difference [22].

\section{Result}

\section{Section I: demographic characteristics of the sample}

100 samples (mothers) were selected from the selected areas of Bagalkot, by using descriptive statistics data were analyzed, presenting of items done by in terms of frequency, percentage and diagram. The frequency and percentage of sample in relation to their demographic characteristics are presented in the following Table 1.

Table 1: Distribution of knowledge scores regarding nutrition for under five children among mothers of selected areas of Bagalkot $\mathrm{n}=100$.

\begin{tabular}{|c|c|c|c|}
\hline Sl No & Respondents & Scores Range & Percentage \\
\hline 1 & 23 & Adequate $(21-30)^{*}$ & $23 \%$ \\
\hline 2 & 41 & Satisfactory $(11-20)^{*}$ & $41 \%$ \\
\hline 3 & 36 & Inadequate $(1-10)^{*}$ & $36 \%$ \\
\hline & Total: 100 & & $100 \%$ \\
\hline
\end{tabular}

Age

(Figure 1)

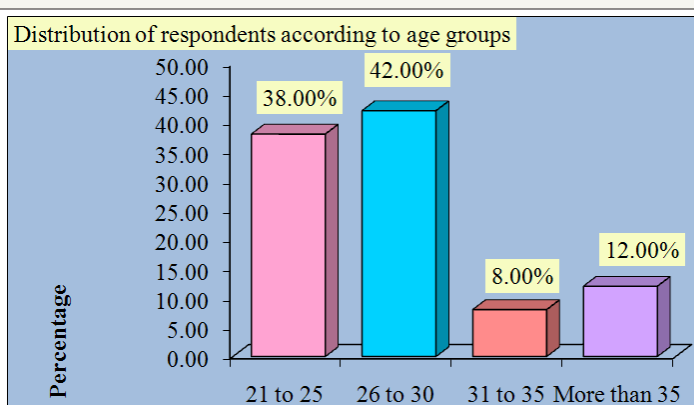

Figure 1: Bar diagram depicting the age wise distribution of the study sample. Majority (42\%) of the sample was between $26-30$ years, $38 \%$ belongs to $21-25$ years, $12 \%$ belongs to more than 35 years and least 08\% was in between $31-35$ years.

\section{Educational qualification}

(Figure 2)

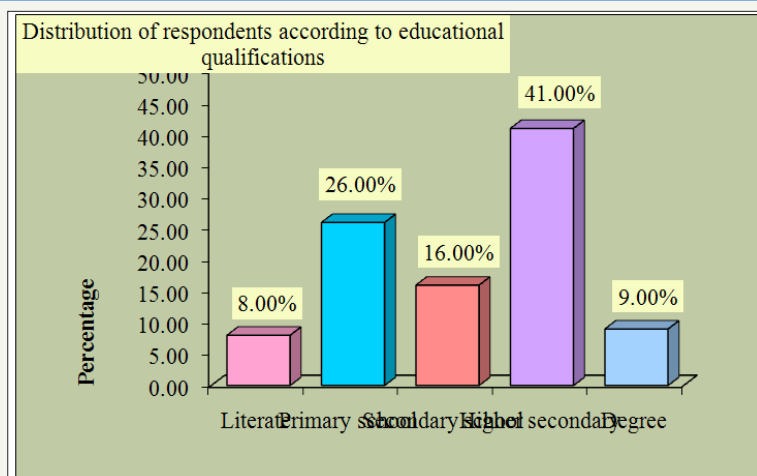

Figure 2: Bar diagram depicting the education qualification wise distribution of the study sample. Majority $(41 \%)$ of the sample completed their higher secondary school, $26 \%$ primary school, $16 \%$ secondary school, $9 \%$ completed their degree and least 08\% (literate) were able to read.

\section{Occupation of mother}

(Figure 3) 


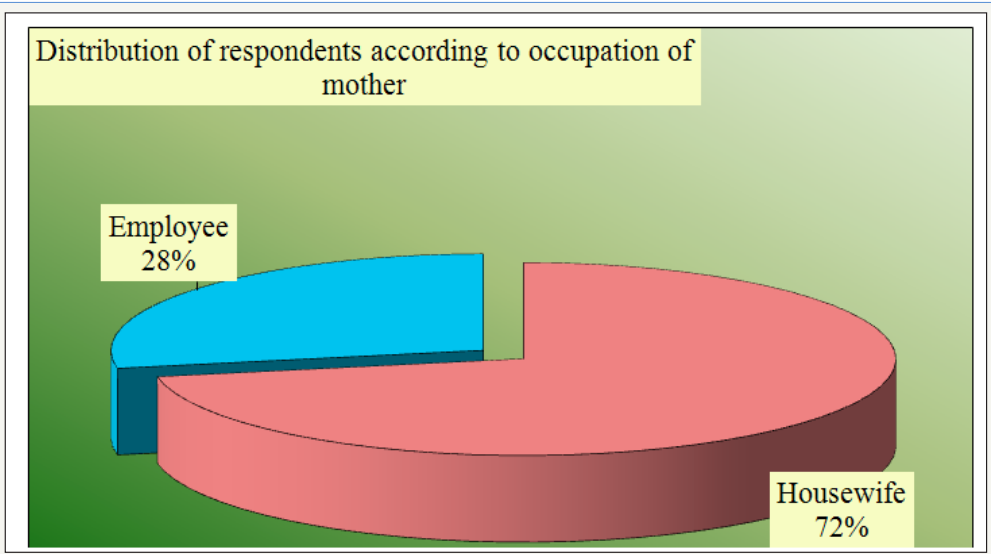

Figure 3: Pie diagram depicting the Occupation of mother wise distribution of the study sample. Majority (72\%) of the sample was housewife and the rest $28 \%$ employee.

\section{Religion}

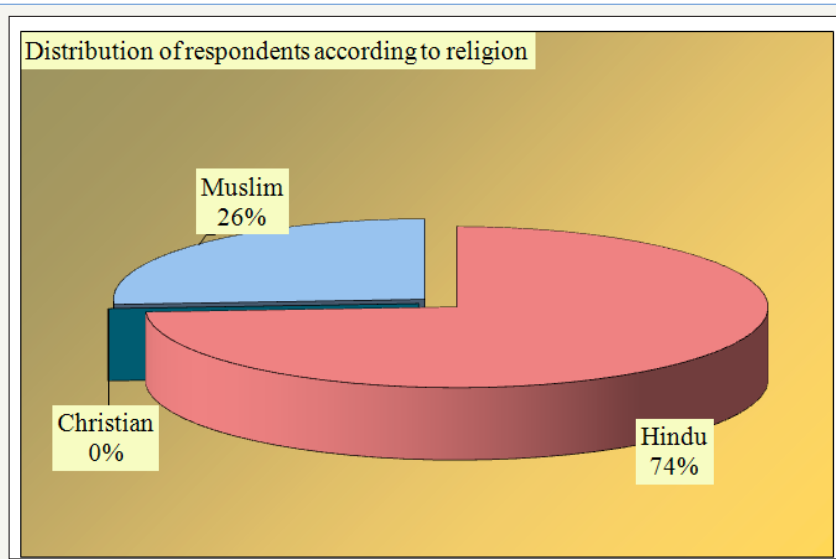

Figure 4: Pie diagram depicting the religion wise distribution of the study sample. Majority (74\%) of the sample were Hindus, while $26 \%$ of the sample were Muslims and no one samples found from Christians religion.

(Figure 4)

\section{Type of family}

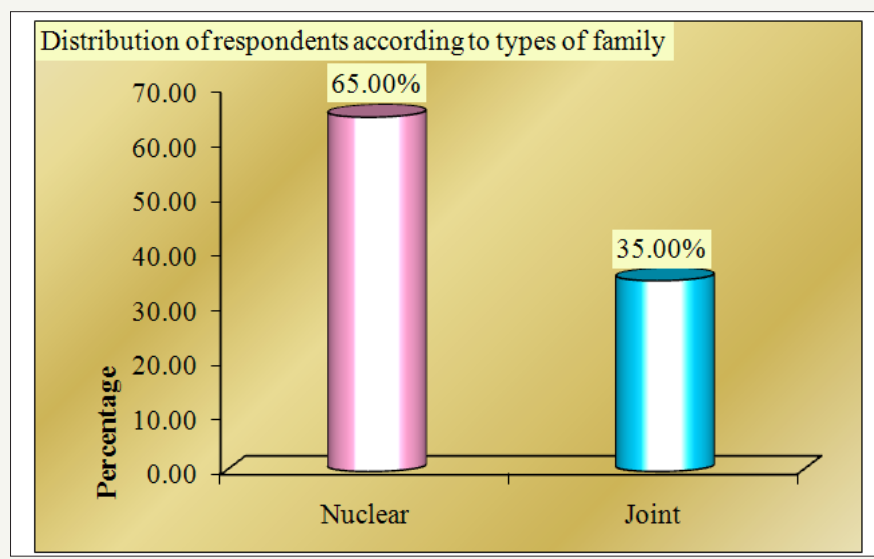

Figure 5: Bar diagram depicting the type of family distribution of the study sample. Majority of $65 \%$ of the samples belongs to nuclear family and $35 \%$ of the samples were belongs to joint family.

(Figure 5)

\section{Marital status}

(Figure 6) 


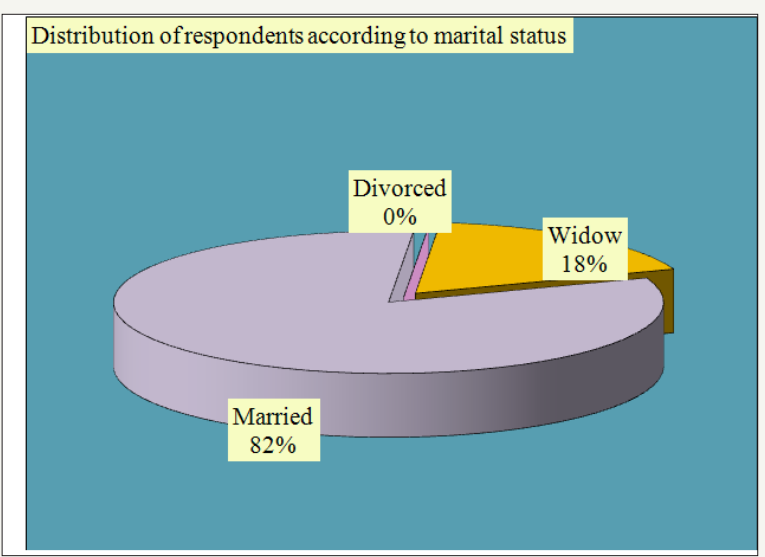

Figure 6: Pie diagram depicting the marital status distribution of the study sample. Most of the mothers $82 \%$ were married, $18 \%$ were widow and no mothers divorced in the samples.

\section{Total number of under five in the family}

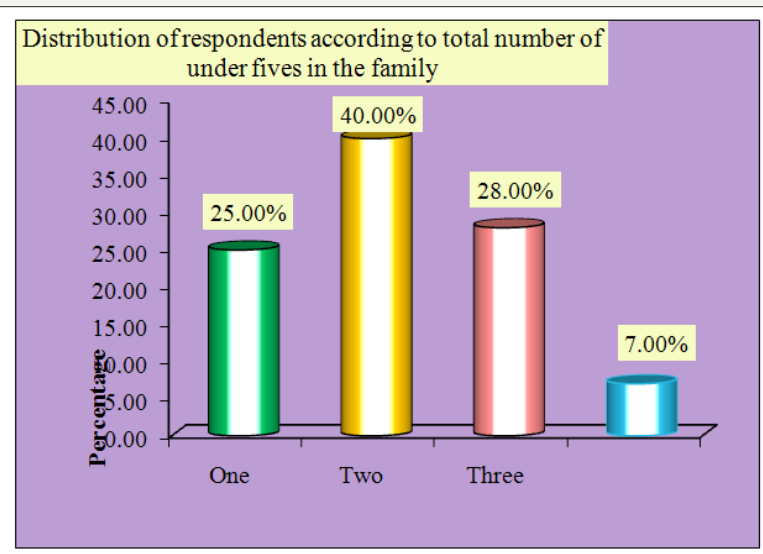

Figure 7: Bar diagram depicting total number of under five in the family wise distribution of the study sample. Majority of $40 \%$ of the sample had a two children in family, $28 \%$ had three children, $25 \%$ had one child and least $07 \%$ had four and above children in the family.

(Figure 7)

\section{Income of the family}

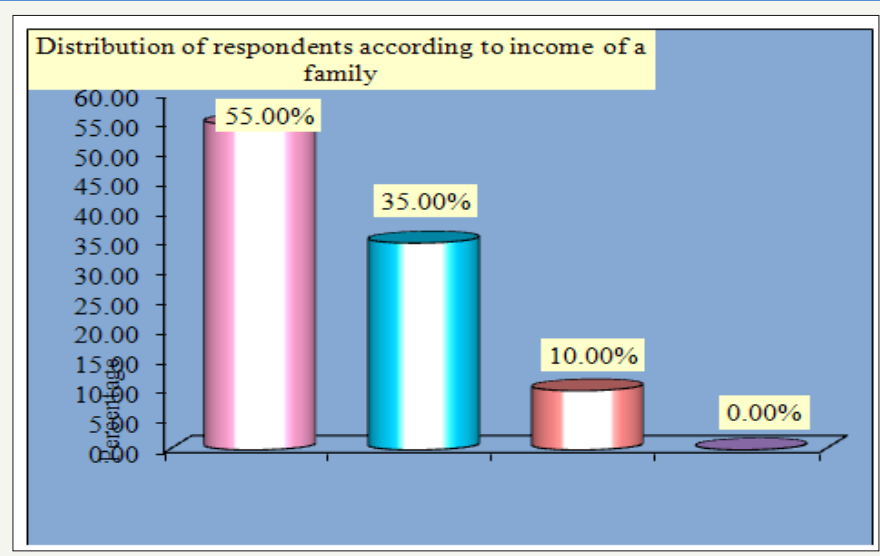

Figure 8: Bar diagram depicting the Income of the family wise distribution of the study sample. Most of the 55\% mothers monthly income was less than Rs 5000/-, 35\% of the mothers had their monthly income Rs 5,001-10,000/-, 10\% of the mothers had 10,001/- to 15,000/- and minimum no one was there $15.001 /$ - and above monthly income.

(Figure 8)

\section{Location}

(Figure 9) 


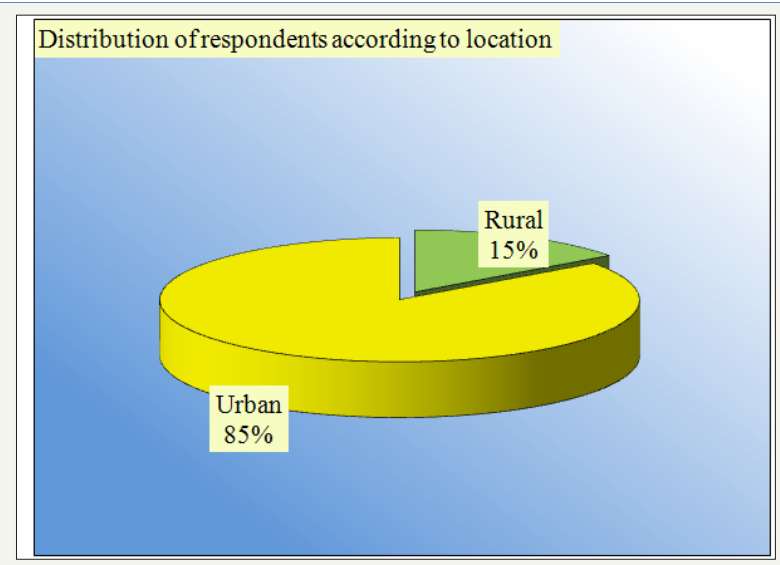

Figure 9: Pie diagram depicting the residential background wise distribution of the study sample. Most $85 \%$ of the mothers residing location was urban and $15 \%$ were in rural area.

Section II: Knowledge of mothers of selected areas of bagalkot regarding for under five children

Knowledge scores obtained by the mothers were tabulated in the master sheet, and data was analyzed in terms of respondents, percentage.The study shows that maximum mothers $41 \%$ had satisfactory knowledge level (41 mothers), inadequate knowledge about $36 \%$ (36 mothers) and 23\% (23 mothers) were had adequate knowledge.The above pie diagram and Table 2 depicts that the majority $41(41 \%)$ of study subjects had satisfactory knowledge and $36,(36 \%)$ of them had inadequate knowledge where as 23 $(23 \%)$ of the study subjects had adequate knowledge regarding nutrition for under five. Thus, the hypothesis [23].

Table 2: Association between level of knowledge and selected demographic variables $n=100$.

\begin{tabular}{|c|c|c|c|c|c|c|c|}
\hline \multirow{2}{*}{ Characteristics } & \multicolumn{3}{|c|}{ Levels of Knowledge } & \multirow{2}{*}{ Chi-Square } & \multirow{2}{*}{ df } & \multirow{2}{*}{ p-Value } & \multirow{2}{*}{ Level of Significance } \\
\hline & Inadequate & Satisfactory & Adequate & & & & \\
\hline \multicolumn{8}{|c|}{ Age } \\
\hline 21 to 25 & 23 & 15 & 0 & \multirow{4}{*}{91.4333} & \multirow{4}{*}{6} & 0 & \multirow{4}{*}{ S } \\
\hline 26 to 30 & \multicolumn{2}{|c|}{26} & 3 & & & \multirow{3}{*}{$* * *$} & \\
\hline 31 to 35 & 0 & 0 & 8 & & & & \\
\hline More than 35 & 0 & 0 & 12 & & & & \\
\hline \multicolumn{8}{|c|}{ Educational Status of Mother } \\
\hline Literate & 8 & 0 & 0 & \multirow{5}{*}{128.299} & \multirow{5}{*}{8} & 0 & \multirow{5}{*}{$S$} \\
\hline Primary school & 26 & 0 & 0 & & & \multirow{4}{*}{$* * *$} & \\
\hline Secondary school & 2 & 14 & 0 & & & & \\
\hline Higher secondary & 0 & 27 & 14 & & & & \\
\hline Degree & 0 & 0 & 9 & & & & \\
\hline \multicolumn{8}{|c|}{ Occupation of Mother } \\
\hline Housewife & 33 & 30 & 9 & \multirow{2}{*}{19.2607} & \multirow{2}{*}{2} & 0.0001 & \multirow{2}{*}{$S$} \\
\hline Employee & 3 & 11 & 14 & & & $* * *$ & \\
\hline \multicolumn{8}{|c|}{ Religion } \\
\hline Hindu & 20 & 31 & 23 & \multirow{2}{*}{14.5017} & \multirow{2}{*}{2} & 0.0007 & \multirow{2}{*}{$S$} \\
\hline Muslim & 16 & 10 & 0 & & & $* * *$ & \\
\hline \multicolumn{8}{|c|}{ Type of Family } \\
\hline Nuclear & 36 & 29 & 0 & \multirow{2}{*}{62.691} & \multirow{2}{*}{2} & 0 & \multirow{2}{*}{ S } \\
\hline Joint & 0 & 12 & 23 & & & $* * *$ & \\
\hline
\end{tabular}




\begin{tabular}{|c|c|c|c|c|c|c|c|}
\hline Married & 30 & 35 & 17 & \multirow{2}{*}{1.3771} & \multirow{2}{*}{2} & \multirow{2}{*}{0.5023} & \multirow{2}{*}{$\mathrm{S}$} \\
\hline Widow & 6 & 6 & 6 & & & & \\
\hline \multicolumn{8}{|c|}{ Total Number of Under Fives in the Family } \\
\hline One & 20 & 5 & 0 & \multirow{4}{*}{82.5131} & \multirow{4}{*}{6} & 0 & \multirow{4}{*}{$S$} \\
\hline Two & 16 & 24 & 0 & & & \multirow{3}{*}{$* * *$} & \\
\hline Three & 0 & 12 & 16 & & & & \\
\hline Four and above & 0 & 0 & 7 & & & & \\
\hline \multicolumn{8}{|c|}{ Monthly Income of the Family } \\
\hline Less than 5000 & 36 & 19 & 0 & \multirow{3}{*}{79.6637} & \multirow{3}{*}{4} & 0 & \multirow{3}{*}{$\mathrm{S}$} \\
\hline Rs:5,001 to Rs 10,000 & 0 & 22 & 13 & & & \multirow{2}{*}{$* * *$} & \\
\hline Rs: 10,001 to Rs 15,000 & 0 & 0 & 10 & & & & \\
\hline \multicolumn{8}{|c|}{ Place of Residence } \\
\hline Rural & 11 & 4 & 0 & \multirow{3}{*}{11.7753} & \multirow{3}{*}{2} & 0.0028 & \multirow{3}{*}{$\mathrm{S}$} \\
\hline Urban & 25 & 37 & 23 & & & $* *$ & \\
\hline Total & 36 & 41 & 23 & & & & \\
\hline
\end{tabular}

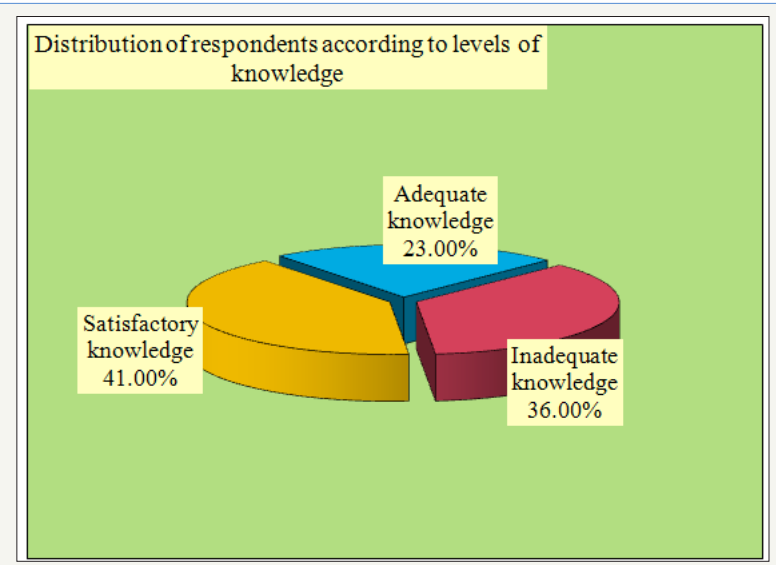

Figure 10: Knowledge scores percentage distribution of mothers regarding nutrition for under five Pie diagram depicting the percentage distribution of the study subjects according to levels of knowledge scores.

$\mathrm{H}_{1}$ : More than 50 percent of mothers will have adequate knowledge regarding nutrition for under-fives was rejected (Figure 10).

\section{Section III: Association between level of knowledge and selected demographic variablesn $=100$.}

The above finding states that "Research hypothesis $\mathrm{H}_{2}$. There will be significant association between knowledge of mothers regarding nutrition for under-fives with selected sociodemographic variables such as age, educational status of mother, occupation of mother, religion, type of family, marital total number of under-fives in the family, monthly income of the family and place of residence stated by the investigator earlier was accepted [24].

\section{Discussion}

Children are the first call agenda of human resource development - not only because young children are the most vulnerable, but because the foundation for life-long learning and human development is laid in these crucial early years. It is now globally acknowledged that investment in human resources development is a pre-requisite for economic development of any nation. Early childhood constitutes the most crucial period in life, when the foundations are laid for cognitive, social, emotional, physical, motor development and cumulative life-long learning [25].

\section{Section I: demographic characteristics of the sample}

A. Age groups of the mothers were in between 21-more than 35 years, in that majority (42\%) of the mothers was between 26-30 years, and least $08 \%$ is more than 35 years.

B. All the mothers had good education, in that majority (41\%) of the mothers completed their higher secondary school and least $08 \%$. were able to read and write (literate).

C. Majority (72\%) of the sample was housewife and the rest $28 \%$ employee.

D. Study shows that maximum mothers $41 \%$ had satisfactory knowledge level (41 mothers), inadequate knowledge about $36 \%$ (36 mothers) and 23\% (23 mothers) were had adequate knowledge [26]. 
E. Testing of hypothesis $\mathrm{H}_{1}$ : More than 50 percent of mothers will have satisfactory knowledge regarding nutrition for underfives was rejected.

\section{Section II: Association between knowledge and selected demographic variables}

A. The present study revealed that there is a significant association between level of knowledge with age $(\chi 2=91.4333$ $\mathrm{P}=0.0000)$.

B. The present study revealed that there is a significant association between level of knowledge with educational status of mother $(\chi 2=128.2990, P=0.0000)$.

C. The present study revealed that there is a significant association between level of knowledge with occupation of mother $(\chi 2=19.2607, P=0.0001)$.

D. The present study revealed that there is a significant association between level of knowledge with monthly income of the family $(\chi 2=79.6637, \mathrm{P}=0.0000)$.

E. The present study revealed that there is a significant association between level of knowledge with place of residence $(\chi 2=11.7753, \mathrm{P}=0.0028)$

It indicates that there is a significant association between knowledge regarding nutrition for under five with selected demographic variables such they include, like age, educational status of mother, occupation of mother, religion, type of family, total number of under-fives in the family, monthly income of the family, place of residence. Therefore, the research hypothesis $\mathrm{H}_{2}$ "There will be significant association between the level of knowledge and selected demographic variables." as stated by the investigator earlier was accepted [27-33].

\section{Conclusion}

\section{Nursing implications}

Nursing is a service-oriented profession and it must advance and keep pace with the advancing technology, newer problemsand growing demands of consumers. The findings of the study have implications for nursing practice, nursing education, nursing administration and nursing research and its implication is not only in the field of nursing but also in other areas like community health, preventive medicine and school health. The present study findings will be helpful for such future studies. In this framework the findings of the study have valuable implications to nursing education, administration and research [34]

\section{Nursing education}

Education is the key to the development of excellent nursing practice. Education faces tremendous challenges in keeping pace with changes in nursing practice to maintain its high quality. Nurses must be lifelong learners and they should be given an opportunity for continuing education. Nurses with higher education deliver cost effective care [35].

A. An awareness need to be created among mothers regarding nutrition for under five children.
B. Nurse educators need to organize regular short-term training programmes, workshops etc., with support of nursing administrator for the mothers about nutrition for under five children [36].

Nursing education programme should also give importance to equip the mothers with adequate skill to provide health education to the individuals, guide other family members in perceiving threat of malnutrition and other deficiency diseases because of lack of nutrition [37].

\section{Nursing practice}

Mothers need to have adequate knowledge regarding nutrition for under fives and how much it is important for children's growth and development. The findings imply that there is a need for regular health education programmes to be carried out by nurses. Counseling centers may be recognized by nurses in colleges to provide counseling and educate mothers on nutrition [37]. Nurse can also identify family members in the same family who have lack of knowledge regarding nutrition and help them to understand the importance and effects of nutrition for growth and development of child, it helps them to adjust with the reasons for why they should start giving proper nutrition. The study throw light on the areas where mother lacks in knowledge regarding nutrition, this will help in the nursing practice to identify the lacunae in the knowledge possessed by the mothers who reside at rural as well urban regarding nutrition. Nurses should try to fill these lacunaes by participating in the preparation of learning resource materials and disseminating these materials through mass media and other ways. Nurses should also involve themselves in counseling mothers to bring changes in their knowledge regarding nutrition for under five.

\section{Nursing administration}

Nurses as an administrator can plan and organize educational programs. Nurse administrator can organize in service education programme for the nurses to increase their knowledge regarding nutrition for under five.Nurses need to involve more actively in the preventive, educating, and giving more education regarding nutrition for under five. Nurse administrator should encourage nurse to involve themselves in preventive programmes on nutrition for under five at primary, secondary and tertiary. Nurse administrator should also plan for continuing nursing education programmes on various aspects of nutrition, which will help the nurses to take care of individuals with behavioral and physical problems and complications of nutritional deficiencies and disorders.

\section{Nursing research}

Research plays a vital role in nursing. There is need for extended and intensive research in the area of educating the staff nurses about nutrition for under five. Research can help and increase the body of nursing knowledge, which improves the care provided. Although actual performance is important, use of observation to explore nurse performance is limited in clinical setting. "The potential of observation in research in this nature has yet to be fully exploited". 


\section{Suggestions}

A. Some educating street play, drama, and other public educating programmes in the community and college should arrange to bring awareness among the mothers and community people regarding nutritional deficiencies.

B. In kinder garden health education can be given to teachers regarding prevention of growth retardation because of nutritional deficiencies.

C. Regular in-service/ refresher course on universal precautions should be implemented in colleges and community.

D. In schools, colleges and community health education can be given regarding nutrition.

E. Nurses should upgrade their knowledge regarding nutrition in order to give excellent education.

F. Mass media, and other medias should strictly give advertise in favor of nutritional deficiencies or community peoples regarding nutrition and its use in growth and development in under five.

G. A suitable environment for study could be maintained through provision of adequate education regarding nutrition and its effects on growth and development.

\section{Recommendations}

Keeping in view the findings of the present study, the following recommendation were made:

A. A comparative study on the effectiveness of the currently advocated nutrition should be under taken with a view to develop problem specific protocols.

B. A study on the knowledge of nursing personnel regarding nutrition may help to the students.

C. A study on the attitude and willingness of slum people regarding nutrition may be helpful for the community.

A qualitative study on the effectiveness of nursing measures to improve the quality of life of persons living with protein energy malnutrition should be conducted.

\section{References}

1. Cranney A, Horsley T, O Donnell S, Weiler H, Puil L, et al. (2007) Effectiveness and safety of vitamin D in relation to bone health. Evid Rep Technol Assess (Full Rep) 158: 1-235.

2. WHO (2005) Breastfeeding and family foods loving and healthy pediatric companion.

3. Yin SA, Li N, Yan ZY, Pan L, Lai JQ, et al. (2009) Effects of nutritional education on improvement of nutritional knowledge of infant's mothers in rural area in China. Zhonghua Yu Fang Yi Xue Za Zhi 43(2): 103-107.

4. National Institute for Nutrition and Food Safety, Chinese Center for Disease Control and Prevention, Beijing, China 43(2): 103-107.

5. Pramod Singh GC, Nair M, Grubesic RB (2009) Factors associated with underweight and stunting among children in rural Terai of eastern Nepal. Asia Pac J Public Health 21(2): 144-152.
6. Ruel MT, Habicht JP (1992) Growth charts only marginally improved maternal learning from nutrition education and growth monitoring in Lesotho. The Journal of Nutrition 122(9): 1772-1780.

7. Sule SS, Onayade AA, Abiona TC (2009) Impact of nutritional education on nutritional status of under-five children in two rural communities of south west Nigeria. Department of Community Health, Obafemi Awolowo University, Ile-Ife 220005, Osun State, Nigeria 16(2): 115-125.

8. Roy SK, Fuchs GJ, Mahmud Z, Ara G, Islam S, et al. (2005) Intensive nutrition education with or without supplementary feeding improves the nutritional status of moderately-malnourished children in Bangladesh J Health Popul Nutr 23(4): 320-330.

9. Ahmed I, Farooq N, Jadoon H, Khalid K, Seema N, et al. (2001) Lactation, breast-feeding supplementation and nutrition. Journal of Ayub Medical College Abbottabad 13(2): 34-37.

10. Ghosh S, Kilaru A, Ganapathy S (2002) Nutrition education and infant growth in rural Indian infants: narrowing the gender gap? J Indian Med Assoc 100(8): 483-484

11. Faruque AS, Ahmed AM, Ahmed T, Islam MM, Hossain MI (2008) Nutrition: basis for healthy children and mothers in Bangladesh. J Health Popul Nutr 26(3): 325-339.

12. Ngare DK, Muttunga JN (1999) Prevalence of malnutrition in Kenya. Department of Behavioural Sciences, Moi University, Eldoret, Kenya 76(7): 376-380

13. Gupta MC, Mehrotra M, Arora S, Saran M (1991) Relation of childhood malnutrition to parental education and mothers' nutrition related KAP. The Indian Journal of Pediatrics 58(2): 269-274.

14. Odunayo SI, Oyewole AO (2006) Risk factors for malnutrition among rural Nigerian children. Asia Pac J Clin Nutr 15(4): 491-495.

15. Cui Y, Yang L, Zhao YX, Wu Q, Tian XB (2008) Study on status of nutrition in children under three years old in rural area in China. National Center for Women and Children and Health, Chinese Center for Disease Control and Prevention, Beijing 100013, China 29(3): 230-234.

16. Ejaz MS, Latif N. Stunting and micronutrient deficiencies in malnourished children. Department of Paediatrics, Dow University of Health Sciences, Karachi, Pakistan.

17. Bhutta ZA (2007) Micronutrient needs of malnourished children. The Aga Khan University, Karachi, Pakistan.

18. Srivatsava N, Sandhu A (2007) Index for measuring child feeding practices. Indian J Pediatr 74(4): 363-368.

19. David P (2003) Nutrition assessment of infant and toddlers. Healthy Child Care.

20. Engle PL, Pelto G, Bentley (2000) Care for nutrition and development. JIMA 98(9): 530-535

21. Gosh S (1997) Integrated Child Development Services Programme Need for Reappraisal. Indian Pediatr 34: 911-918.

22. Child Malnutrition and feeding practices in Malawi.

23. Park k (2005) Parks text book of preventive and social medicine. $\left(18^{\text {th }}\right.$ edn), Banarsidas Bhanot, Jabalpur, India, p. 399.

24. Basavanthappa (2005) Nursing research. Jaypee Brothers, New Delhi, India, pp. 113-123.

25. Linkages Facts for feeding. Academy for Educational development. 1825 Connecticut, Ave, Washington, USA.

26. Redding AB, Marlow RD (2005) Text book of pediatric Nursing. ( $6^{\text {th }}$ edn), Elsevier, New Delhi, India, pp. 584-588.

27. Mitra M, Kumar PV, Chakrabarty S, Bharath P (2007) Nutritional status of kamar tribal children in Chhittisgarh. Indian J Peadtr 74(4): 381-384 
28. Sachdev HPS (1997) Nutrition status of children and women in india, recent trends. Nutrition foundation of India Events at NFI. pp. 1-5.

29. Sharma S, Nagar S (2006) Impact of educational intervention on knowledge of mothers regarding child care and nutrition in Himachal Pradesh. J Soc Sci 12(2): 139-142.

30. Nyarucucha CN, Msuya JM, Mamira PS, Kerengi AJ (2006) Nutritional status and Feeding Practives of under five children in Simanjiro Dt. Tanzania. Tanzania Health Research Bulletin 8(3): P162-167.

31. Ray SK, Biswas AB, Kumar S (2002) A study of Dietary Pattern, Household Food Security and Nutritional Profile of Under-five Children of a Community of West Bengal. JIMA advertiser, Culcatta, India 98(9): 519.

32. Kumar D, Goel NK, Poonam Sing, Mittal (2006) Influence of infant feeding practices on nutritional status of under five children. Indian J Pediatr May 73(5): 417-421.
33. Yadav RJ, Singh P (2007) Factors influencing Nutritional Status of Children in Bihar, India.

34. Potter PA, Perry AG (2005) Fundamentals of Nursing. ( $6^{\text {th }}$ edn), Mosby, New Delhi, India, pp. 91-92.

35. Hannan A, Hassan MQ, Fazlur AK, Rahman A. Infant feeding practices from birth to 2 years of age and nutritional status of children and mothers in Bangladesh. 10 ${ }^{\text {th }}$ ASCON Abstract No: 133, Dhaka 1362, Bangladesh.

36. Kamau TF, O Mwega GM, Muita JW (2002) Child care practices and nutritional status of children aged 0-2 years in Thika, Kenya. East Afr Med J 79(10): 524-529.

37. Ruel MT, Menon P (2002) Child feeding practices are associated with child nutritional status in Latin America: innovative used of the demographic and health surveys. J Nutr Jun 132(6): 1180-1187.
Creative Commons Attribution 4.0 International License

For possible submissions Click Here

\section{Submit Article}

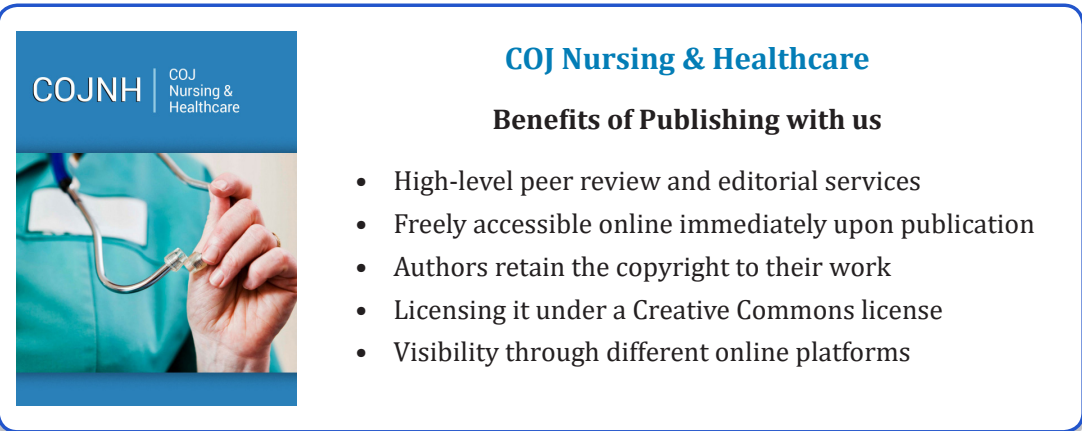

